\title{
Insulin responses to varying profiles of subcutaneous insulin infusion: kinetic modelling studies
}

\author{
E. W. Kraegen and D.J. Chisholm \\ Garvan Institute of Medical Research, St. Vincent's Hospital, Sydney, Australia
}

\begin{abstract}
Summary. Refinement of continuous subcutaneous insulin infusion for diabetes therapy requires improved knowledge of subcutaneous insulin absorption kinetics. We have used kinetic modelling to quantitate systemic insulin delivery produced by subcutaneously-infused insulin (i.e. simulated meal and basal delivery). Profiles were studied in normal subjects, with endogenous insulin suppressed. Paired studies of intravenous insulin infusion enabled systemic insulin delivery to be quantitated. High rate subcutaneous delivery ( $10 \mathrm{U}$ in $5 \mathrm{~min}$ ) resulted in a systemic delivery of approximately $8 \mathrm{U}$ in $4 \mathrm{~h}$. Increasing infused insulin concentration delayed systemic delivery $(p<0.025)$. Both continuous and pulsatile low-rate infusions $(2.4 \mathrm{U} / \mathrm{h})$ gave similar slow increases in systemic delivery to $1 \mathrm{U}$ after $4 \mathrm{~h}$. Computer fitting to a two-pool model of the subcutaneous space suggested a low rate of insulin deg-
\end{abstract}

radation for all profiles (rate constant $<10 \% / \mathrm{h}$ ). We conclude that: (1) systemic insulin delivery following subcutaneous infusion conforms reasonably to a two-pool model, (2) subcutaneous insulin degradation is low regardless of input profile, (3) a long delay in basal systemic delivery should be taken into account when initiating or resuming interrupted subcutaneous insulin infusion. Kinetic modelling of subcutaneous insulin absorption should be useful to predict the impact of programming strategies for continuous subcutaneous insulin infusion therapy.

Key words: Subcutaneous insulin, administration and dosage, blood, time factors, injections, insulin, pharmacodynamics, mathematical modelling.
Widespread interest in continuous subcutaneous insulin infusion (CS II) for diabetes therapy has led to an interest in quantitation of absorption kinetics of subcutaneously-infused insulin. Processes such as local tissue accumulation versus degradation of insulin and time delays in systemic delivery rates need clarification. In addition the influence of concentration of infused insulin needs to be studied further. A kinetic model of these processes should have predictive value and aid in the further refinement of CSII.

Classic studies of subcutaneous insulin absorption have given us some knowledge in the area [1, 2]. However these studies were not performed with the aim of assessing the particular delivery patterns used with CSII and the methods then used are subject to problems of interpretation. Tracer studies of the disappearance of insulin from the injection site may not reflect true systemic insulin delivery rates of biologically active insulin in the presence of local tissue degradation of insulin [3]. In studies of CSII there is a paucity of data on serum insulin levels and where information is available [4] there is a problem of interpretation of free insulin levels in the presence of insulin antibodies.
In a previous study [5], we proposed the use of a hypoglycaemic blood glucose clamp in normal subjects to create a situation in which endogenous insulin release is suppressed and serum insulin levels are directly related to the entry of subcutaneous insulin into the vascular system. In this and in a similar study, using somatostatin to block endogenous insulin secretion [6], the object of insulin administration was simulation of the normal insulin response to a mixed meal. A wider range of subcutaneous insulin infusion profiles have now been studied and are reported here. In addition, we have applied kinetic modelling techniques to interpret the original data and new data. Our aims were to estimate the fate of subcutaneously administered insulin and its dependence on the infusion profile, and to relate our findings to the therapeutic application of CSII.

\section{Subjects and methods}

\section{Subjects}

Studies were performed on a total of ten normal subjects aged $20-24$ years. All subjects were within $10 \%$ of their ideal body weight (Metropolitan Life Insurance Tables). The experimental protocol was 
approved by the Hospital Ethics Committee and possible risks were explained to all subjects before voluntary consent was obtained. Subjects were studied after an overnight fast.

\section{General aspects of experimental studies}

Insulin was delivered into the $\mathrm{SC}$ tissue of the anterior abdominal wall of normal subjects via a 25 gauge needle. Where insulin was delivered over a short time period (up to $30 \mathrm{~min}$ ) a protocol (designated protocol A) was followed as described previously [5]: that is, IV infusion of insulin at $1-1.4 \mathrm{U} / \mathrm{h}$ and glucose (variable rate) was used to clamp blood glucose between 2.5 and $3.0 \mathrm{mmol} / 1$ to suppress endogenous insulin release. This infusion, into the arm contralateral to that used for sampling, commenced $60 \mathrm{~min}$ before SC insulin and continued throughout the study. Serum immunoreactive insulin (IRI) increments above the plateau level created by the IV infusion were used to indicate absorption from the SC site. Where SC insulin was infused over a period of $4 \mathrm{~h}$, the IV insulin infusion was omitted and interpretation of serum insulin levels was made only beyond the first hour (designated protocol B). In all studies, neutral highly-purified porcine insulin (Actrapid MC, $40 \mathrm{U} / \mathrm{ml}$, Novo, Denmark) was used. Where necessary this was diluted using normal saline for SC infusion or using polygeline solution (Haemaccel, Hoechst-Behringwerke, FRG) for IV infusion [7] by a peristaltic pump (Model 531, IVAC Corporation, California).

\section{Specific experimental studies}

Rapid SC delivery (simulated meal delivery). Ten units SC insulin were administered to four normal, non-obese, overnight-fasted subjects by constant infusion over $5 \mathrm{~min}$ at a concentration of $40 \mathrm{U} / \mathrm{ml}$. Protocol A was used to block endogenous insulin production. The studies were compared with similar, earlier studies on the same subjects where insulin was infused over 5 or $30 \mathrm{~min}$ at a concentration of $3.3 \mathrm{U} / \mathrm{ml}$ [5]. Dilute insulin was administered first in three subjects, and last in one subject, with an interval of 5-7 days between studies.

Pulsed versus continuous insulin delivery (simulated basal delivery). Many insulin infusion devices deliver insulin in the basal mode as a series of small pulses rather than as a continuous infusion. To investigate whether pulsatile delivery alters absorption kinetics, insulin was infused $\mathrm{SC}$ at a rate of $2.4 \mathrm{U} / \mathrm{h}$ into six overnight-fasted subjects by continuous flow $(40 \mathrm{U} / \mathrm{ml}, 60 \mu \mathrm{l} / \mathrm{h})$ or by pulsatile flow $(40 \mathrm{U} / \mathrm{ml}$, one $15 \mu \mathrm{l}$ pulse every $15 \mathrm{~min}$ ) in paired studies on separate occasions. Most insulin infusion devices now available employ insulin delivery in the basal mode between these extremes. Serum insulin was measured over a 4-h period.

Systemic insulin distribution kinetics. Values of metabolic clearance rate (MCR) and total distribution volume (TDV) of insulin are required in order to quantitate systemic appearance rates of SC insulin. To calculate these an additional IV infusion study was performed in subjects who previously received rapid SC delivery. An IV infusion profile was used (Fig. 1) which produced serum insulin levels approximating those previously produced by rapid SC delivery. The IV profile, previously used by us for control of post-meal hyperglycaemia by the IV route [8], delivered $7.5 \mathrm{U}$ over a 2 -h period. The calculation of MCR and TDV over a range of insulin variation similar to that following rapid SC delivery was designed to minimise any possible departure from first order kinetics in systemic insulin distribution. The IV profile was superimposed on the constant insulin infusion of $1 \mathrm{U} / \mathrm{h}$ IV insulin (protocol A) used to suppress endogenous insulin secretion.

\section{Theoretical studies}

Two theoretical models were examined as an aid to interpreting experimental data. In the first a single pool (Fig. 2) was envisaged for $\mathrm{SC}$ distribution of insulin; this assumes that all SC insulin is immedi-
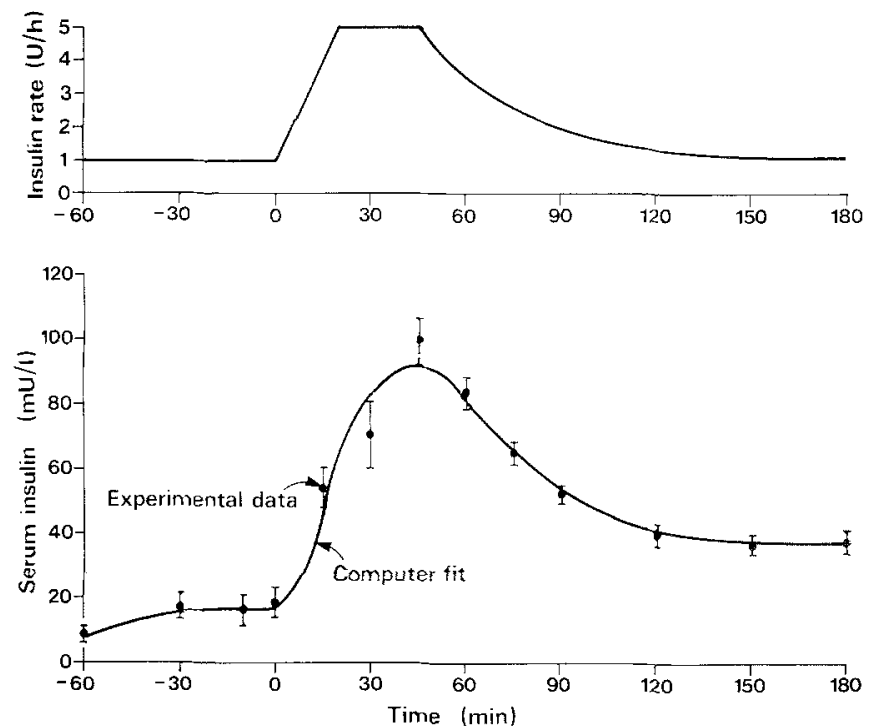

Fig. 1. Top panel: intravenous insulin infusion used to calculate metabolic clearance rate and total distribution volume. Bottom panel: computer fit to the serum insulin response $(n=4)$ following the IV infusion. Mean \pm SEM shown
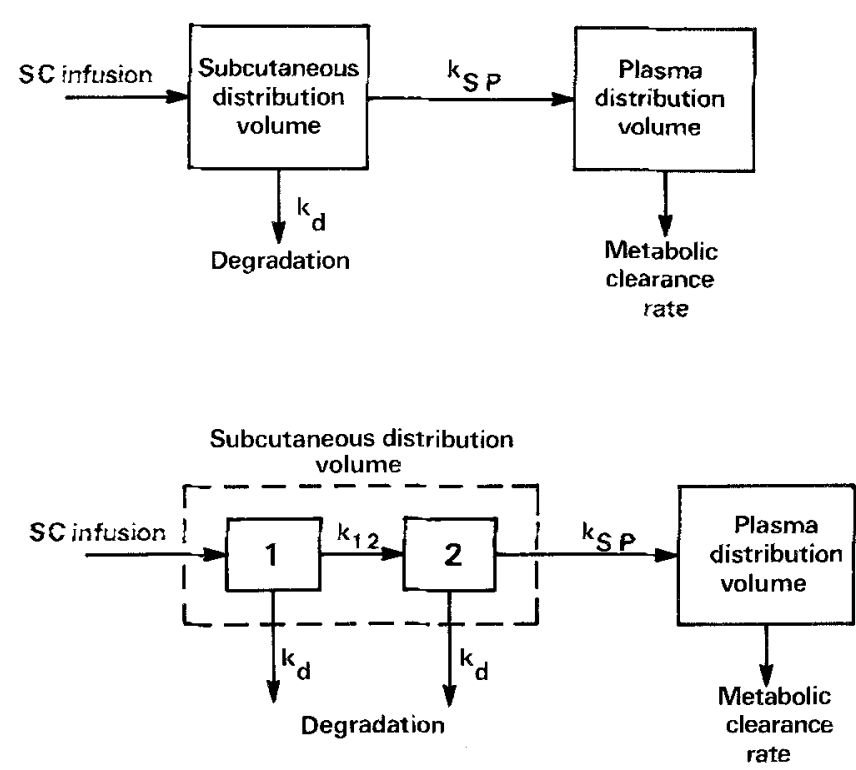

Fig. 2. Top panel: single-pool (Model 1). Bottom panel: Split-pool (Model 2) model of subcutaneous space for insulin. Rate constants are described in the text

ately available for transcapillary absorption. As this assumption seemed an oversimplification a second, two-pool model of SC insulin distribution was proposed (Fig.2). Here insulin was assumed to move from a first to a second pool (perhaps in the vicinity of the capillary wall) before absorption. Our rationale was to seek a minimal model which would give a reasonable agreement with experimental data [9]. Both models assume a fractional rate of systemic delivery $k_{\mathrm{sp}}$ and a degradation rate constant $k_{d}$ from the respective $S C$ pool (the process labelled as "degradation" may include insulin which is irreversibly bound to SC tissue as well as insulin which is physically degraded; no distinction can be made mathematically between these possibilities). When protocol A was pursued an IV infusion of insulin constituted an additional entry into the plasma compartment (not shown). 
The mathematical formulae representing the theoretical models are as follows:

Model 1

$\frac{d x}{d t}=S(t)-k_{s p} x-k_{d} X$

$\frac{d y}{d t}=k_{s p} x-\frac{M C R}{T D V} y+I(t)$

Model 2

$\frac{\mathrm{dx}_{1}}{\mathrm{dt}}=\mathrm{S}(\mathrm{t})-\mathrm{k}_{\mathrm{d}} \mathrm{x}_{1}-\mathrm{k}_{12} \mathrm{x}_{1}$

$\frac{\mathrm{dx}_{2}}{\mathrm{dt}}=\mathrm{k}_{12} \mathrm{x}_{1}-\mathrm{k}_{\mathrm{d}} \mathrm{x}_{2}-\mathrm{k}_{\mathrm{sp}} \mathrm{x}_{2}$

$\frac{d y}{d t}=k_{s p} x_{2}-\frac{M C R}{T D V} y+I(t)$

where $\mathrm{x}$ is amount of SC insulin in single pool (Model 1), $\mathrm{x}_{1}, \mathrm{x}_{2}$ are amounts of SC insulin in pools 1 and 2 respectively (Model 2), $\mathrm{k}_{12}, \mathrm{k}_{\mathrm{d}}$, $\mathrm{k}_{\mathrm{sp}}$ are rate constants as indicated in Figure 2, S(t) and $\mathrm{I}(\mathrm{t})$ are $\mathrm{SC}$ and IV insulin infusion rates respectively, $y$ is amount of insulin in the total distribution volume (TDV), and MCR is metabolic clearance rate of insulin. (For both models plasma insulin concentration $\mathrm{C}$ is given by $\mathrm{C}=\mathrm{y} / \mathrm{TDV}$ ). The model properties were studied in two ways. (a) General model behaviour was studied using a BASIC program incorporating a fourth order Runge-Kutta integration routine on a PDP 11/03 computer (Digital Equipment Corporation, Maynard, Massachusetts, USA); (b) The models were fitted to experimental data using a Fortran nonlinear regression program (MODFIT) written for this type of application [10]. The model equations were contained in a subroutine to MODFIT. This procedure gave estimates of the rate constants and pool masses of insulin following each SC insulin input profile and also an estimate of the time variation of systemic insulin appearance rate of $\mathrm{SC}$ insulin [equal to $\mathrm{k}_{\mathrm{sp}} \mathrm{x}_{2}$ in $\mathrm{Eq}$ [5]]. Note that calculation of systemic insulin appearance rate depends principally on the parameters MCR and TDV and similar rates are obtained using Models 1 and 2.

\section{Analytical techniques}

Blood glucose was estimated using a Yellow Springs 23 AM Glucose Analyser (Yellow Springs, Ohio, USA). Serum insulin and C-peptide were measured by radioimmunoassays using second antibody separation. Reagents for the C-peptide assay were supplied by the Novo Research Institute, Denmark [11].

Statistical levels of inference were determined using Student's ttest.

\section{Results}

\section{Determination of metabolic clearance rate and total distribution volume}

Figure 1 shows the IV insulin infusion profile given to obtain quantitative estimates of MCR and TDV for systemic insulin distribution and clearance. This profile was added to a constant IV infusion of IU/h beginning $1 \mathrm{~h}$ previously which suppressed blood glucose from $5.0 \pm 0.2$ to $3.0 \pm 0.1 \mathrm{mmol} / 1$ and endogenous insulin secretion (C-peptide to $<0.2 \mu \mathrm{g} / \mathrm{l}$ ) during the study. Figure 1 also shows the mean serum insulin response and the best computer fits found by solving Eq. 2 (or 5) with the first term on the righthand side equal to zero (i.e., no SC input), and adjusting constants MCR and

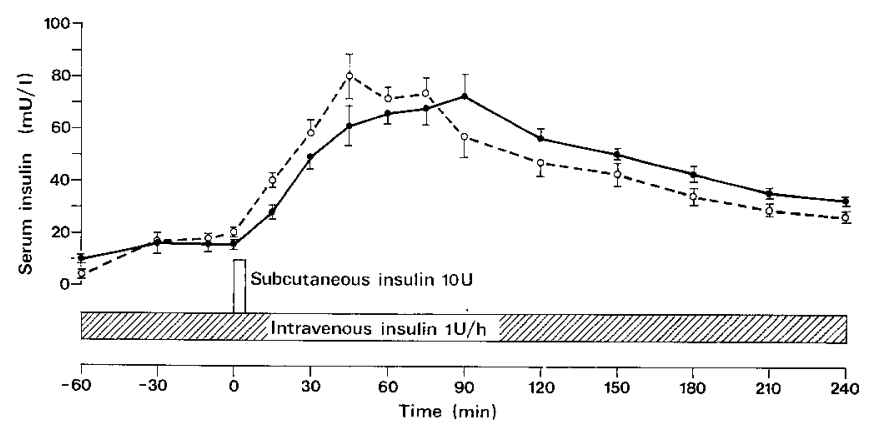

Fig. 3. Serum insulin responses $(n=4)$ to infusion of $10 \mathrm{U}$ of SC insulin over $5 \mathrm{~min}$ at concentrations of 40 (broken line) and $3.3 \mathrm{U} / \mathrm{ml}$ (solid line). A 5-h infusion of $1 \mathrm{U} / \mathrm{h}$ IV insulin was administered to lower blood glucose and block endogenous insulin. Mean \pm SEM shown

TDV by the computer program MODFIT. Best fit values were MCR: $0.6041 / \mathrm{min}$ per $\mathrm{m}^{2}$ and TDV: $6.71 \mathrm{l} / \mathrm{m}^{2}$.

\section{Additional SC infusion studies}

Effect of concentration. Figure 3 shows the time profile obtained with $10 \mathrm{U}$ of $40 \mathrm{U} / \mathrm{ml}$ insulin infused over $5 \mathrm{~min}$ and compares this with the previously reported profile obtained with diluted insulin $(3.3 \mathrm{U} / \mathrm{ml})$ in the same subjects. There was a consistent delay of 15-30 $\mathrm{min}$ in serum insulin response to concentrated insulin, compared with that to dilute insulin. Areas under the insulin response curve above the plateau established by IV infusion were significantly greater over the period $0-60 \min (p<0.025)$ with dilute SC insulin (i.e. with increased volume of infusion), indicating faster absorption. The incremental areas from 0 to $240 \mathrm{~min}$ were, however, not significantly different, suggesting that SC insulin degradation was not strongly influenced by volume of infusion.

Most of the variation in peak insulin responses and incremental areas in the SC studies at the two concentrations appeared related to between-subject, rather than within-subject, variation. There was a similar ranking from low to high responders in each case and paired differences in peak levels were $<10 \mathrm{mU} / 1$ in three out of four subjects.

Prolonged low-level insulin infusion (simulated basal infusion). An infusion rate of $2.4 \mathrm{U} / \mathrm{h}(40 \mathrm{U} / \mathrm{ml})$ over $4 \mathrm{~h}$ was chosen to represent prolonged basal SC infusion. This was administered to the same six subjects on two occasions by continuous flow $(40 \mathrm{U} / \mathrm{ml}, 60 \mu \mathrm{l} / \mathrm{h})$ or by pulsatile flow $(40 \mathrm{U} / \mathrm{ml}, 15-\mu \mathrm{l}$ pulse every $15 \mathrm{~min})$. Serum insulin responses are shown in Figure 4 . After $4 \mathrm{~h}$ of SC infusion, blood glucose fell to $3.3 \pm 0.2$ and $3.5 \pm$ $0.2 \mathrm{mmol} / 1$ in the two studies respectively. Insulin levels rose slowly to reach $18 \pm 4$ and $22 \pm 4 \mathrm{mU} / 1$ at $4 \mathrm{~h}$ for continuous and pulsatile delivery respectively, and in both cases $\mathrm{C}$-peptide levels fell to negligible values ( $<20 \%$ of basal). There was no significant difference - between the two studies in levels of insulin, C-peptide or blood glucose at any point. 


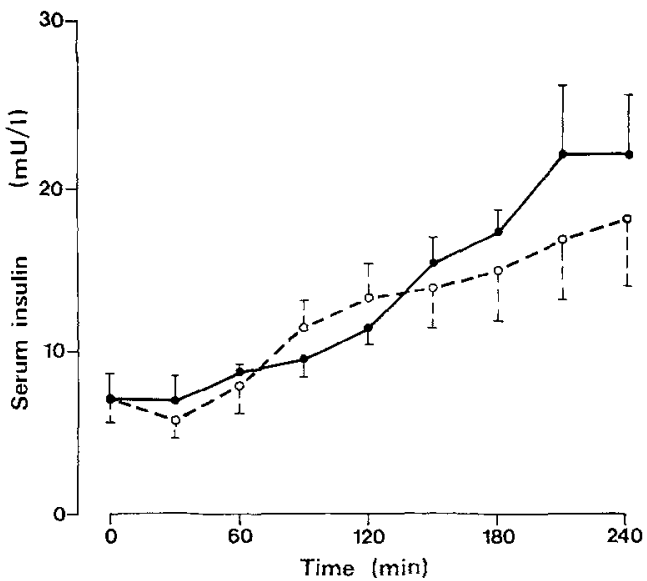

Fig.4. Serum insulin responses $(n=6)$ to continuous $(40 \mathrm{U} / \mathrm{ml}$, $60 \mu \mathrm{l} / \mathrm{h}$, broken line) and pulsatile $(40 \mathrm{U} / \mathrm{ml}, 15-\mu \mathrm{l} \mathrm{pulse} / 15 \mathrm{~min}$, solid line) infusion of $2.4 \mathrm{U} / \mathrm{h}$ insulin. Mean \pm SEM shown

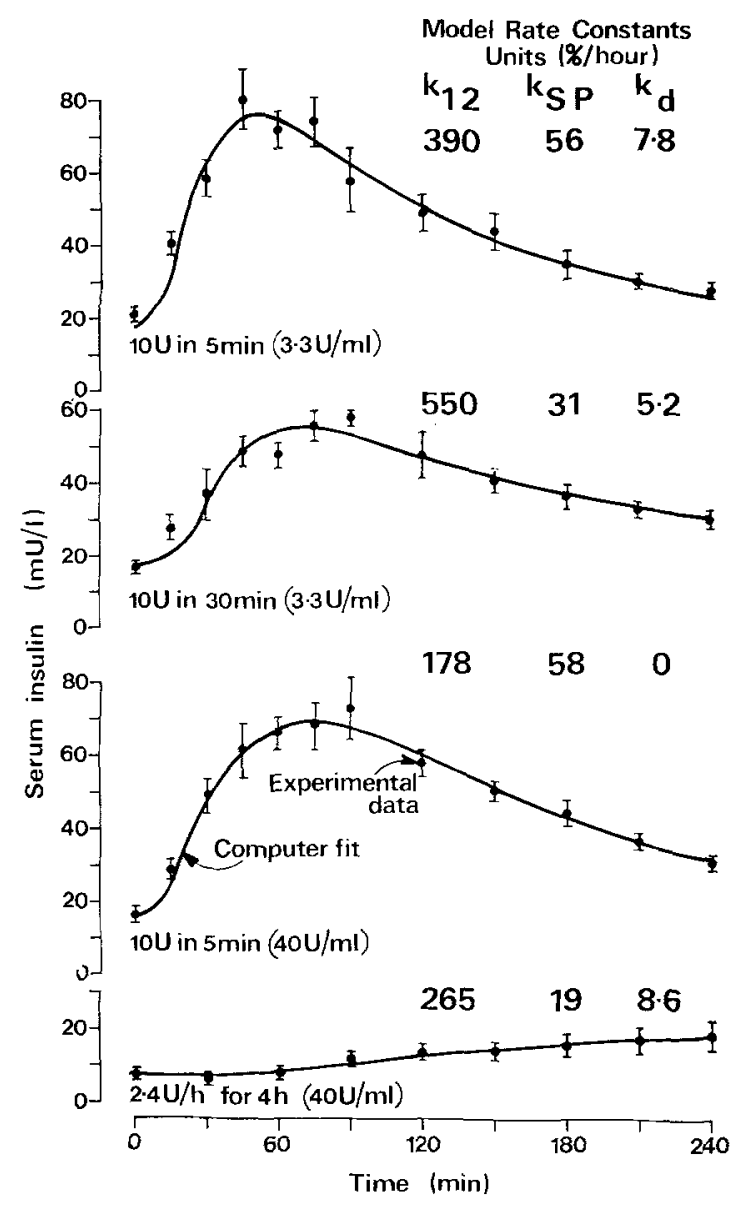

Fig. 5. Computer fits using Model 2 (split-pool model) to mean serum insulin responses shown in Figures 3 and 4 (continuous infusion), and to responses to an infusion of $10 \mathrm{U}$ insulin over $30 \mathrm{~min}$ as described previously [5]. Model rate constants for the best fit are shown. Lowest curve $n=6$, other curves $n=4$. Mean \pm SEM shown

\section{Kinetic analysis of SC-infused insulin}

Computer fits to experimental responses. Models 1 and 2 $\mathrm{s}$,'e applied to the analysis of data shown in Figures 3 and 4 . In addition previously-reported responses to $10 \mathrm{U}$ insulin infused $\mathrm{SC}$ over $30 \mathrm{~min}(3.3 \mathrm{U} / \mathrm{ml})$ were in-

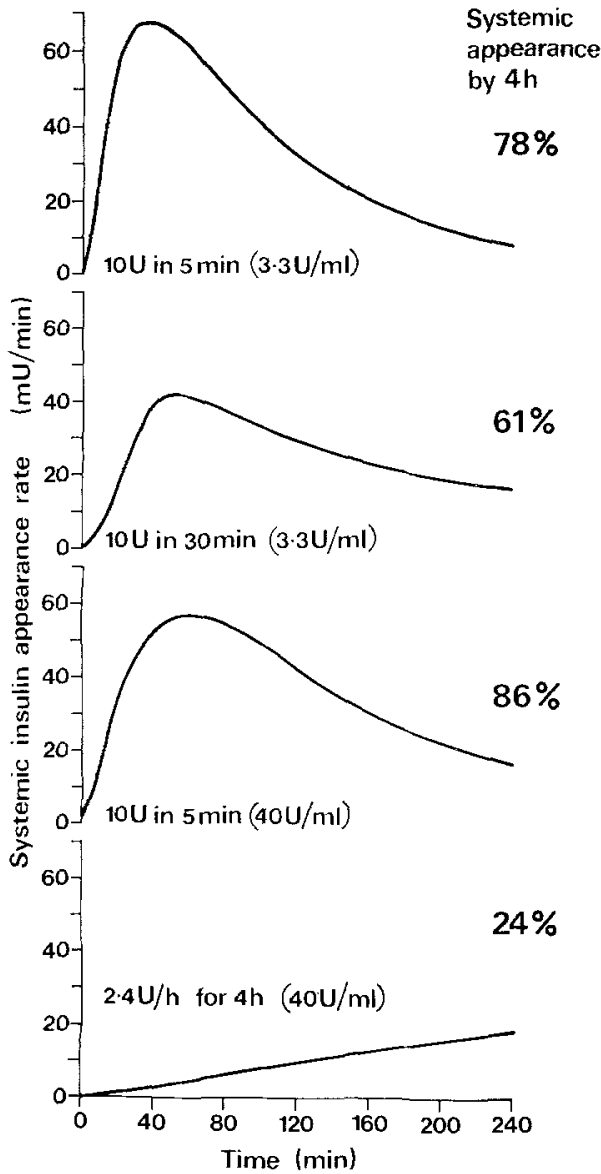

Fig. 6. Computer-predicted systemic appearance rates of insulin for the four profiles shown in Figure 5. Shown also are estimates of total systemic appearance of insulin delivered over a 4-h period (percentage of administered insulin)

cluded [5]. Because of the similarity in responses to continuous and pulsatile low-level insulin delivery only the former was subjected to analysis. As MCR and TDV were determined separately, only two constants $\left(\mathrm{k}_{\mathrm{d}}, \mathrm{k}_{\mathrm{sp}}\right)$ were available to fit Model 1 and three constants $\left(\mathrm{k}_{\mathrm{d}}, \mathrm{k}_{\mathrm{sp}}\right.$ and $\mathrm{k}_{12}$ ) to fit Model 2. Model 1 failed to give satisfactory fits in any case (results not shown). When constants were adjusted to fit the tail of the serum insulin response the predicted initial rise was much faster than that observed experimentally.

In contrast excellent fits were obtained using Model 2. Computer fits are shown in Figure 5 with the best-fit values of the rate constants. While there was some variation it is clear that $\mathrm{k}_{12}$ was high in all cases (corresponding to a rapid movement of insulin from pool 1 to pool 2), with $\mathrm{k}_{\mathrm{sp}}$ largely determining systemic insulin delivery in all but the initial stages following SC insulin administration. It is also of note that the rate constant of insulin degradation $\mathrm{k}_{\mathrm{d}}$ was $<10 \% / \mathrm{h}$ in all cases.

Fate of administered insulin. Figure 6 displays predicted systemic insulin appearance rates with cumulative systemic appearance of SC-administered insulin over the 4-h period, expressed as a percentage of administered 


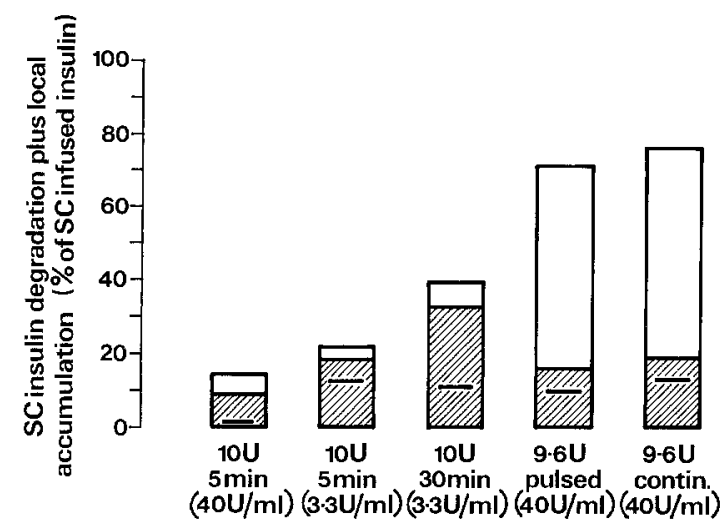

Fig. 7. Computer estimates of degradation and local accumulation of insulin in SC tissue for the SC inputs studied (expressed as a percentage of administered insulin). The best-fit value (solid bar) and the possible range (shaded area) of degradation are shown

insulin. Approximately $80 \%$ of administered insulin had appeared by $4 \mathrm{~h}$ with the 5 -min infusions (78\% in $3.3 \mathrm{U} / \mathrm{ml}$ study; $86 \%$ in $40 \mathrm{U} / \mathrm{ml}$ study). This dropped to $61 \%$ for the 30 -min infusion. Relatively little $(20 \%-$ $30 \%$ ) of the continuous low-level SC insulin infusion had appeared in the circulation by $4 \mathrm{~h}$, and it is of note that the estimated systemic entry rate at $4 \mathrm{~h}$ is approximately $50 \%$ of the SC infusion rate of $40 \mathrm{mU} / \mathrm{min}$ $(2.4 \mathrm{U} / \mathrm{h})$.

Figure 7 shows estimates of mean degradation and local accumulation of insulin. A distinction between these is necessarily imprecise. However, the best-fit value for total insulin degraded over the 4-h period was $<20 \%$ of administered insulin in all cases.

\section{Discussion}

While mathematical models have been proposed for the systemic handling of IV infused insulin $[12,13]$, there are no counterparts for the more complex situation of continuous SC insulin infusion. A monoexponential decay curve may be adequate to fit some $[2,14]$ but not all $[1,3]$ data on disappearance of trace radiolabelled insulin following bolus injection. Our simple model (Model 1), which assumes that all SC-administered insulin is available for immediate transcapillary absorption, would not fit serum insulin response to $\mathrm{SC}$ insulin infusion. In particular Model 1 does not account for an initial time lag $\left(\mathrm{t}_{1 / 2}\right.$ of $8-24 \mathrm{~min}$ - calculated from $\mathrm{k}_{12}$ in Model 2 of $180 \%$ to $550 \% / \mathrm{h}$ ). The split-pool model of SC insulin kinetics (Model 2) takes into account the initial absorption delay and gives a good fit to mean serum insulin curves following a variety of SC inputs.

Prior quantitation of MCR and TDV of insulin by IV infusion allows systemic insulin delivery rates to be estimated directly from serum insulin response curves. This method is not affected by possible local SC degradation of insulin [3]. However, interpretation is based on the assumption that the $\mathrm{SC}$ route does not alter biologi- cal activity of insulin without a corresponding change in immunological activity. Supporting this assumption is the equivalent degree of blood glucose suppression observed during prolonged infusion via the two routes [18]. Values for MCR and TDV found here agree well with other values reported $[12,15]$. Nevertheless, it is important to obtain specific values of MCR and TDV in individual subjects. A preliminary theoretical analysis [16], made when only literature values [15] were available, resulted in overestimation of SC insulin degradation.

Our results, taken with previously reported data, demonstrate a slight but significant delay (15-20 min) in $\mathrm{SC}$ insulin absorption with increased concentration. This was reflected in Model 2 by a reduction in $\mathrm{k}_{12}$ suggesting a delay in the movement of insulin to a region allowing transcapillary absorption. Clinically allowance could be made for use of more concentrated insulin by commencing the meal pulse about $15 \mathrm{~min}$ before the meal rather than coincident with the meal(s) [5]. In further studies (not shown) we have found that the absorption delay associated with $100 \mathrm{U} / \mathrm{ml}$ compared with $40 \mathrm{U} / \mathrm{ml}$ insulin could be almost exactly offset by bolus rather than 5-min delivery.

There was some variation in model parameters $\left(\mathrm{k}_{12}\right.$, $\mathrm{k}_{\mathrm{sp}}$ and $\mathrm{k}_{\mathrm{d}}$ ) according to the SC insulin input. Nevertheless some consistent patterns emerge. The constant $k_{12}$, which largely determines the initial rate of increase of serum insulin, is large, varying from $180 \%$ to $550 \% / \mathrm{h}$. The constant $\mathrm{k}_{\mathrm{sp}}$, which has an increasing influence on serum insulin levels over the later time course, is lower, varying from $20 \%$ to $60 \%$. The half-time ( $\left.\mathrm{t}_{1 / 2}\right)$ of removal of insulin from pool 2 (given by $70 / \mathrm{k}_{\mathrm{sp}}$ ) is approximately $70 \mathrm{~min}$ for the rapid 5 -min infusions, agreeing well with mean estimates of $t_{1 / 2}$ for disappearance of radiolabelled insulin following abdominal bolus administration of $87 \mathrm{~min}$ [1], $76 \mathrm{~min}$ [2] and $120 \mathrm{~min}$ [14]. We estimate approximately $80 \%(78 \%-86 \%)$ of SC insulin is absorbed over $4 \mathrm{~h}$ following rapid SC infusions.

Our results however suggest a reduction in absorption rate constant (increase in half-life) during prolonged delivery at lower rates (simulated basal delivery); during infusion of $2.4 \mathrm{U} / \mathrm{h}$ of $40 \mathrm{U} / \mathrm{ml}$ insulin, systemic insulin delivery was only about $1.2 \mathrm{U} / \mathrm{h}$ after $4 \mathrm{~h}$. This appeared to increase marginally but not significantly with pulsatile administration. The rate of $2.4 \mathrm{U} / \mathrm{h}$ was moderately above the usual basal rate for CSII, but was chosen to produce serum insulin levels which could be measured with reasonable precision.

Variation of the model constants according to the type of input infusion suggests that the linear model is an oversimplification, and indicates directions for improvement. For example, there may be some local reversible binding of insulin delaying absorption at low infusion rates, with saturation of the binding at high infusion rates.

Another consistent pattern which has emerged is the low rate (best fit, $\mathrm{K}_{\mathrm{d}}<10 \% / \mathrm{h}$ ) of $\mathrm{SC}$ degradation re- 
gardless of SC input. The extent of SC degradation in man has not been clear [21-23]. In our studies concentration of SC insulin infused had little effect on SC insulin degradation. While the distinction between locally degraded and accumulated insulin is necessarily imprecise, our best-fit parameters correspond to $<20 \%$ total degradation of SC administered insulin over the 4-h period. Thus the slow initial rate of systemic delivery of insulin associated with prolonged (basal) infusion is associated with local accumulation rather than degradation or irreversible loss of SC insulin. This is consistent with considerable differences in response to matched infusions of SC and IV insulin over 1-2 h [17], but with steady state insulin levels during 8-h SC infusions of approximately $80 \%$ of that produced by IV infusion [18].

A limitation to our study has been the restriction of modelling studies to mean responses for each SC input rather than fitting individual responses. This practice has previously been used in modelling to identify characteristics defining an 'average' person [19]; studies on a larger group of subjects will be necessary to analyse individual variation. Also results are reported only in normal subjects and responses may differ in the diabetic population. Nevertheless preliminary studies in insulindependent diabetes, using free insulin levels suggest that SC degradation is no greater than in normal subjects [20].

In conclusion, kinetic modelling is a useful way of quantitating systemic appearance of $\mathrm{SC}$ insulin and provides a rational basis for examining the fate of $\mathrm{SC}$ infused insulin and its relationship to patterns of administration. This information should be particularly useful in programming the second-generation devices for CSII which are now becoming available. For example a relatively long time delay ( $\mathrm{t}_{1 / 2}$ of $3-4 \mathrm{~h}$ ) in systemic insulin delivery following changes in basal SC delivery rate should be taken into account, particularly when commencing or resuming interrupted CSII therapy.

Acknowledgements. The expert assistance of G.S.Zelenka, S. Furler and M.J.Hewett with theoretical and clinical aspects is gratefully acknowledged. This study was supported by the National Health and Medical Research Council of Australia.

\section{References}

1. Binder C (1969) Absorption of injected insulin. Acta Pharmacol Toxicol 27 (Suppl 2): 1-87

2. Joiner CL (1959) Rate of clearance of insulin labelled with ${ }^{131} \mathbf{I}$ from the subcutaneous tissues in diabetic and normal subjects. Lancet 1:964-967

3. Berger M, Halban PA, Girardier L, Seydoux J, Offord RE, Renold AE (1979) Absorption kinetics of subcutaneously injected insulin. Evidence for degradation at the injection site. Diabetologia 17 : 97-99

4. Champion MC, Shepherd GAA, Rodger NW, Dupre J (1980) Continuous subcutaneous infusion of insulin in the management of diabetes mellitus. Diabetes 29: 206-212
5. Chisholm DJ, Kraegen EW, Zelenka GS (1981) Programming of insulin delivery with meals during subcutaneous insulin infusion. Diabetes Care 4: 265-268

6. Home PD, Pickup JC, Keen H, Alberti KGMM, Parsons JA, Binder C (1981) Continuous subcutaneous insulin infusion: comparison of plasma insulin profiles after infusion or bolus injection of the mealtime doses. Metabolism 30: 439-442

7. Kraegen EW, Lazarus L, Meler H, Campbell LV, Chia YO (1975) Carrier solutions for low-level intravenous insulin infusion. $\mathrm{Br}$ Med J 3: $464-466$

8. Kraegen EW, Chisholm DJ, McNamara M (1981) Timing of insulin delivery with meals. Horm Metab Res 13: 365-367

9. Bergman RN, Cobelli C (1980) Minimal modelling, partition analysis, and the estimation of insulin sensitivity. Fed Proc 39: $110-115$

10. McIntosh JEA, McIntosh RP (1980) Mathematical modelling and computers in endocrinology. In: Gross F, Grumbach MM, Labhart A, Lipsett MB, Mann T, Samuels LT, Zander J (eds) Monographs in endocrinology, Vol 16. Springer Verlag, Berlin, pp 250-293

11. Heding LG (1975) Radioimmunological determinations of human C-peptide in serum. Diabetologia 11: $541-548$

12. Sherwin RS, Kramer KJ, Tobin JO, Insel PA, Liljenquist JE, Berman M, Andres R (1974) A model of insulin kinetics in man. J Clin Invest 53: 1481-1492

13. Serge G, Turco GL, Varcellone G (1973) Modelling blood glucose and insulin kinetics in normal, diabetic and obese subjects. Diabetes 22: 94-103

14. Koivisto VA, Felig P (1980) Alterations in insulin absorption and in blood glucose control associated with varying insulin injection sites in diabetic patients. Ann Int Med 92: 59-61

15. Navalesi R, Pilo A, Ferrannini E (1978) Kinetic analysis of plasma insulin disappearance in non-ketotic diabetic patients and in normal subjects. A tracer study with ${ }^{125}$ I-insulin. J Clin Invest 61 : 197-205

16. Kraegen EW, Chisholm DJ, Zelenka GS (1981) Plasma insulin responses to varying profiles of open-loop subcutaneous insulin infusion in man. In: Irsigler K, Kunz KM, Owens DR, Regal H (eds) New approaches to insulin therapy, MTP Press, Lancaster, pp 25-30

17. Katsilambros N, Verykokidou H, Philipides P, Moiras G, Daikos GK (1979) Comparison of intravenous and subcutaneous insulin infusions in man. Lancet 1:609-610

18. Kraegen EW, Chisholm DJ, Hewett MJ (1983) Comparison of plateau insulin levels achieved by intravenous or subcutaneous insulin infusion: evidence for low rates of subcutaneous degradation. Diabetes Care 6: 118-121

19. Cobelli C, Federspil G, Pacini G, Salvan A, Scandellari C (1982) An integrated mathematical model of the dynamics of blood glucose and its hormonal control. Math Biosci 58:27-60

20. Kraegen EW, Chisholm DJ, Hewett MJ, Furler S (1983) Low subcutaneous degradation and slow absorption of insulin in diabetics during the basal mode of CSII. Diabetes 32: (Suppl 1), 70A

21. Pickup JC, Keen H, Stevenson RW, Parsons JA, Alberti KGMM, White M, Kohner EM (1978) Insulin via continuous subcutaneous infusion. Lancet 2: 988-989

22. Duckworth WC, Kitabchi AE (1981) Insulin metabolism and degradation. Endocr Rev 2: 210-232

23. Berger M, Cuppers HJ, Halban PA, Offord RE (1980) The effect of aprotinin on the absorption of subcutaneously injected regular insulin in normal subjects. Diabetes 29:81-83

Received: 28 January 1983

and in revised form: 25 July 1983

Dr. E. W. Kraegen

Garvan Institute

St. Vincent's Hospital

Sydney, NSW 2010

Australia 